\title{
HÁ ALTERNATIVAS AO USO DOS TRANSGÊNICOS?
}

HUGH LACEY

\section{RESUMO}

Aexistência ou não de alternativa ao uso de transgênicos capaz de satisfazer a demanda mundial por alimento e nutrientes é uma questão que permanece aberta à investigação científica. A importância dos transgênicos ainda não está bem fundamentada no conhecimento científico disponível, em parte porque as conquistas e o potencial da agroecologia não foram objeto de atenção científica suficiente.

PALAVRAS-CHAVE: Transgênicos; agroecologia; pesquisa científica; agricultura.

\section{SUMMARY}

Whether or not there are alternatives to using transgenics, that would be able to satisfy the world's food and nutrition needs, remains open to further scientific investigation. The necessity for using transgenics is not currently well based on available scientific knowledge, in part because the achievements and potential of agroecology have received insufficient scientific attention.

KEYWORDS: Transgenics; agroecology; scientific research; agricultural alternatives.

A biotecnologia tornou-se um fator decisivo para a trajetória da economia internacional. Esse cenário é bem recebido pelas instituições científicas, porque assegura financiamentos para pesquisas e empregos para cientistas, numa época em que o apoio governamental à ciência é cada vez menor. O mesmo acontece com as instituições comerciais, uma vez que o desenvolvimento de inovações biotecnológicas voltadas para o mercado (como a tecnologia dos transgênicos) é dotado de uma aura científica, o que torna possível minar a credibilidade dos seus críticos, cuja posição é definida como "anticientífica" e pautada por agendas ideológicas. 
As pesquisas científicas decerto levaram ao desenvolvimento (bem como à ratificação da eficácia) das aplicações atuais dos transgênicos, como culturas de plantio resistentes a herbicidas específicos e outras às quais incorporaram-se, por meio da engenharia genética, características que funcionam como pesticidas. Eé possível afirmar, com uma boa margem de segurança, que outras aplicações estejam a caminho. A eficácia por si só e a pesquisa que a confirma, todavia, não liquidam todas as questões acerca do valor social e da legitimidade do uso disseminado de transgênicos, tampouco do lugar que cabe, nas políticas nacionais e internacionais, à pesquisa, ao desenvolvimento eà implementação prática de uma agricultura baseada em transgênicos. Tais questões implicam algumas indagações: 1. a agricultura baseada em transgênicos é capaz de desempenhar um papel relevante e indispensável para satisfazer as demandas de alimentação e nutrição de todas as populações, e pode-se esperar que isso aconteça sob as condições socioeconômicas em que está sendo implantada? 2. há sérios riscos implicados que não são compensados pelos benefícios e não podem ser administrados de forma adequada no contexto de uma política regulamentar judiciosa? 3. existem alternativas "melhores", ou seja, alternativas que propiciem maiores benefícios e envolvam menos riscos? ${ }^{1}$ Neste artigo, abordarei sobretudo a terceira questão: as alternativas ao uso dos transgênicos, suas possibilidades de implementação e os tipos de pesquisa científica que podem contribuir para esclarecê-las.

\section{A INVESTIGAÇÃo CIENTífiCA E O CONTEXTO SOCIOECOLÓGICO}

A apreciação crítica dessas questões obviamente deve refletir os compromissos éticos e socioeconômicos, e isto explica, em parte, por que permanece muitas vezes enredada em controvérsias insolúveis ${ }^{2}$. Não obstante isso, pode-se e deve-se fundamentá-las com informações oriundas de investigações empíricas sistemáticas (ou seja, científicas), relevantes e apropriadas, cuja metodologia deve levar em conta os contextos social e socioecológico da produção e distribuição de produtos agrícolas. Porém, as pesquisas que deram origem ao desenvolvimento dos transgênicos descontextualizam, ou seja, investigam as características que se desejam dessas culturas, suas bases genéticas e as condições químicas e biológicas das quais dependem, utilizando estratégias usuais das pesquisas da biologia molecular e da biotecnologia. Tais estratégias enquadram-se no que chamo de abordagem descontextualizada: sujeitados às suas restrições, os objetos e as respectivas possibilidades são investigados nos termos dos seus componentes, processos, interações e estruturas subjacentes, bem como das leis que os governam, de forma desassociada dos contextos humano, social e ecológico nos quais estão inseridos e são utilizados³.
[1] Lacey, H. A controvérsia sobre os transgênicos: questões científicas e éticas. São Paulo: Idéias e Letras, 2006.

[2] Idem, "On the interplay of the cognitive and the social in scientific practices". Philosophy of Science, n. 72, pp. 977-88, 2005.

[3] Para mais detalhes ver idem, Is science value free? Values and scientific understanding. Londres: Routledge, 1999; e "Existe uma distinção relevante entre valores cognitivos e sociais?" Scientiae Studia, n. 1, pp.121-49, 2003. 
[4] Considerar, como exemplo, os riscos em idem, $A$ controvérsia sobre os transgênicos: questões cientificas e éticas, op. cit., cap. 4; e "O Princípio de Precaução e a autonomia da ciência". Scientia Studia, n. 4, pp.373-92, 2006.
Os transgênicos são claramente objetos biológicos e uma boa quantidade de conhecimentos sobre eles e suas potencialidades pode ser obtida por pesquisas que adotam a abordagem descontextualizada. Entretanto, os transgênicos não são apenas objetos biológicos, mas também socioeconômicos: são, na maior parte, mercadorias ou detentores de direitos de propriedade intelectual. Não levar em consideração o contexto socioeconômico impede que os benefícios, os riscos e as alternativas sejam investigados de forma apropriada. Embora as pesquisas moleculares e biotecnológicas subjacentes ao desenvolvimento e à implementação da tecnologia de transgênicos sejam indispensáveis à investigação, não são suficientes, pois estão alienadas dos seus contextos.

\section{RIscos}

Os riscos potenciais do uso dos transgênicos podem advir do seu caráter biológico ou socioeconômico ${ }^{4}$. As avaliações de risco-padrão lidam com os riscos diretos (de curto prazo) à saúde humana e ao ambiente, associados a mecanismos biológicos, químicos, bioquímicos e físicos, cujas quantidades possam ser quantificadas e as probabilidades, estimadas. São avaliações que se fundamentam em pesquisas realizadas pela abordagem descontextualizada. Portanto, ignoram os riscos de longo prazo e raramente colocam em prática a monitoração sistemática dos efeitos acumulativos potenciais, sobre a saúde e o meio ambiente, do cultivo e do consumo de transgênicos; ignoram, igualmente, os riscos indiretos potenciais implicados nos contextos e mecanismos socioeconômicos, como os riscos à biodiversidade pelo uso disseminado de monoculturas transgênicas, as ameaças à viabilidade de formas alternativas de agricultura (por exemplo, a orgânica), e as ameaças à segurança do mundo resultantes de um cenário onde corporações privadas controlem de forma ainda mais ampla os recursos mundiais de alimentos e sementes.

Esses riscos não são apenas largamente desconsiderados, como também descartados de forma efetiva, quando os cientistas alegam, com foros de autoridade, que o uso dos transgênicos não causa riscos sérios que não possam ser compensados pelos benefícios que traz e administrados mediante uma política regulamentar com base legal. Essa alegação, contudo, não representa, nem poderia representar, um dado científico estabelecido, a menos que os riscos indiretos fossem investigados. A não realização de pesquisas relevantes sobre os riscos indiretos repercute essa convicção, comum no meio científico, de que a investigação se torna "menos científica" caso não seja redutível a pesquisas que adotam a abordagem descontextualizada. Tal perspectiva, porém, não cumpre plenamente as finalidades da ciência. Isto pode ser 
difícil de aceitar, pois, segundo a tradição da ciência moderna, a pesquisa científica caracteriza-se pela aplicação da abordagem descontextualizada, embora essa visão sempre estivesse em tensão com outra, que fundamenta o meu argumento: a de que a investigação científica deve ser sistemática, empírica e mantida conforme os padrões de objetividade, e, portanto, incluir não apenas a física nuclear e a biologia molecular, entre outras, mas também as ciências sociais e ecológicas.

Para alguns, a convicção de que a abordagem descontextualizada é parte essencial da investigação científica baseia-se em pressupostos materialistas ou reducionistas, em uma visão metafísica segundo a qual todos os fenômenos são passíveis de explicação (por princípio) por categorias admissíveis no âmbito da abordagem descontextualizada, uma visão que, ela própria, não pode ser confirmada pela abordagem descontextualizada5. Para outros, a convicção nessa abordagem está vinculada à consciência de que a sua adoção da abordagem descontextualizada seja a fonte das descobertas tecnocientíficas e, de forma mais geral, fundamente-se nas relações de reforço mútuo existentes entre os valores do progresso tecnológico e a aceitação da alegação de que a abordagem descontextualizada serve efetivamente para definir a metodologia única para a ciência ${ }^{6}$. Além disso, uma outra convicção impõe-se, inconteste entre os progressistas, de que, primeiro, a tecnociência seja uma fonte de inovações, de valor e poder insuperáveis, que aumenta o bem-estar humano e soluciona problemas (incluindo aqueles causados pelas aplicações tecnológicas dos resultados científicos); e, segundo, que as inovações tecnocientíficas prima facie tenham valor social generalizado, não estando apenas a serviço de interesses particulares, de forma que a sua implantação normalmente é justificável em termos éticos e sociais7. Quando visões como essas preponderam, as preocupações com riscos indiretos esmaecem, tornam-se insignificantes, e até mesmo a sugestão de que a implementação dos transgênicos em larga escala deva ser desacelerada para dar tempo às investigações empíricas acerca dos riscos potenciais é interpretada como uma oposição ao desenvolvimento científico ${ }^{8}$. Essa posição tende a predominar onde há poderosas relações de reforço mútuo (fortalecidas pela importância cada vez maior da biotecnologia) entre os interesses comerciais e os valores do progresso tecnológico.

\section{ALTERNATIVAS}

As metodologias das pesquisas biotecnológicas são insuficientes (embora necessárias) para a investigação não apenas da gama completa de riscos potenciais resultantes da utilização de transgênicos, mas também das possibilidades produtivas, entre outras, de formas alternativas de agricultura, como a agroecologia. No parágrafo ante-
[5] Idem, "Existe uma distinção relevante entre valores cognitivos e sociais?", cit. Marcelo Leite discute como as visões metafísicas, assim como o materialismo e o determinismo, serviram para privilegiar as metodologias reducionistas, em vez de as interacionistas, nas pesquisas biológicas (Promessas do genoma. São Paulo: Editora da UNESP, 2007).

[6] Lacey, H. "As formas nas quais as ciências são e não são livres de valores". Crítica, n. 6, pp. 89-111, 2000; e "Existe uma distinção relevante entre valores cognitivos e sociais?", cit.

[7] Idem, "As formas nas quais as ciências são e não são livres de valores", cit.

[8] Idem, A controvérsia sobre os transgênicos:questõescientíficase éticas, op.cit. 
rior, mencionei dois conjuntos de relações de reforço mútuo: 1. entre progresso tecnológico e exclusividade da abordagem descontextualizada; e z. entre comércio e progresso tecnológico. Quando as relações do segundo conjunto são fortes, as instituições científicas tendem a não levar a sério a possibilidade de haver alternativas corroboráveis por conhecimentos científicos obtidos por meio de metodologias não redutíveis à abordagem descontextualizada.

$\mathrm{Na}$ verdade, os porta-vozes das instituições científicas e agroindustriais proeminentes reiteram com insistência que não há alternativas de cultivo que possam substituir as técnicas baseadas em transgênicos, e que possam produzir, de forma satisfatória, maiores benefícios em termos de produtividade, sustentabilidade e satisfação das necessidades humanas, sem incorrer em riscos inaceitáveis, como não produzir alimentos suficientes para alimentar e nutrir a crescente população mundial ou ser inviáveis nas regiões do mundo que sofrem com a fome crônica, intensificada ainda mais pelas mudanças climáticas. Os transgênicos, insistem, são necessários para alimentar o mundo nas próximas décadas e, sobretudo, exigidos em caráter de urgência nas regiões mais pobres, onde as condições agrícolas foram devastadas. Essa insistência é fundamentada em resultados científicos ratificados ou demonstra um alinhamento às instituições políticas e socioeconômicas predominantes, cujas trajetórias solapam as condições necessárias para que as alternativas se desenvolvam e prosperem?

As evidências de que as pesquisas científicas atuais não confirmam a não-existência de alternativas são cada vez maiores. Tais evidências sustentam que os métodos agroecológicos (em conjunto com outras alternativas) que estão sendo e podem ser desenvolvidos têm capacidade para gerar uma alta produtividade em culturas essenciais e, ao mesmo tempo, com menos riscos. Além disso, mesmo que a agricultura baseada em transgênicos seja capaz de alimentar o mundo, podem existir alternativas "melhores". Mais especificamente, pode existir uma diversidade de métodos alternativos complementares, específicos ao local, que, a um só tempo, (a) produzam gêneros alimentícios nutritivos, ambientalmente sustentáveis, que protejam a biodiversidade e fortaleçam as comunidades locais; (b) estejam mais em sintonia com as aspirações das comunidades rurais e as variações regionais e culturais; (c) sejam capazes de desempenhar um papel integral na produção dos alimentos necessários para abastecer a crescente população mundial; e (d) sejam particularmente apropriados para garantir que as populações rurais dos países "em desenvolvimento" recebam alimentos e nutrientes suficientes, de forma que, sem a sua consolida[9] Ibidem, cap. 5 . ção, é provável que os padrões atuais de fome persistam².

A agroecologia é, em particular, uma alternativa que se destaca. É uma forma de agricultura fundamentada por resultados científicos 
derivados da utilização de metodologias não enquadradas pela abordagem descontextualizada:

A agroecologia éconsiderada uma disciplina cientifica que transcende os limites da própria ciência, ao pretenderincorporar questões não tratadas pela ciência clássica (relações sociais de produção, eqüidade, segurança alimentar, produção para auto consumo, qualidade de vida, sustentabilidade ${ }^{10}$.

Mais que isso, os seus métodos são apropriados para a investigação das três questões mencionadas, os benefícios, os riscos e as alternativas; e, no Brasil, estudos científicos ${ }^{11}$ e um crescente movimento rural dão uma forte sustentação à agroecologia ${ }^{12}$. O principal objeto de investigação da agroecologia, como disciplina científica, é o agroecossistema, isto é, o sistema socioecológico em que a produção agrícola e a distribuição dos seus produtos acontecem. Logo, a investigação agroecológica, diferentemente das realizadas por meio da abordagem descontextualizada, não pode ser reduzida a uma pesquisa sobre processos, interações, estruturas e legislações subjacentes aos componentes dos agroecossistemas. Os ecossistemas, nesse tipo de investigação, são tratados a um só tempo como locais e integrantes de um sistema socioeconômico mundial ${ }^{13}$, incluindo análises de como se relacionam com os requisitos almejados: produtividade, sustentabilidade (integridade ecológica e preservação da biodiversidade), saúde social, respeito às tradições culturais e fortalecimento da atuação das populações locais. Todas essas análises incluem, ainda, descobrir as condições sob as quais os requisitos desejados podem ou não ser concretizados em um equilíbrio adequado (e como variam de acordo com o local), bem como os princípios que os explicam ${ }^{14}$.

Em outro trabalho, documentei alguns dos sucessos da agroecologia como uma abordagem às atividades agrícolas, e ofereci uma perspectiva geral dos estudos que demonstram como, em determinadas condições, a capacidade produtiva da agroecologia não é inferior às técnicas agrícolas convencionais ou baseadas em transgênicos ${ }^{15}$. Esses sucessos comprovam a promessa da agroecologia, em particular aos que não são beneficiários da expansão das empresas agroindustriais; porém, sem esforços maiores de pesquisa, a extensão de tal promessa não pode ser determinada. Mesmo assim, em razão do número insuficiente de pesquisas relevantes que possam fornecer as evidências, os defensores da utilização de transgênicos podem retorquir - corretamente, ainda que de forma enganosa - que não há prova científica de que uma das abordagens alternativas, ou mesmo todas em conjunto, complementando-se, apresente uma produtividade suficiente para abastecer o mundo com alimentos ${ }^{16}$. No entanto, esta réplica é irrelevante, como deixa claro a seguinte passagem:
[10] EMBRAPA(Grupo de trabalho em agroecologia). Marco referencial $\mathrm{em}$ agroecologia. Brasília: EMBRAPA Informação Tecnológica, 2006, p.42.A propósito do pluralismo de metodologias nas pesquisas agrícolas, ver Gomes,J.C.C. \& Rosenstein, S. "Ageração do conhecimento na transição agroambiental: em defesa da pluralidade epistemológica e metodológica na prática científica". Cadernos de Ciência e Tecnologia, n. 17, pp. 29-57, 2000; Gomes, J. C. C. "Bases epistemológicas da agroecologia”. In: Aquino, A. M. de \& Assis, R. L.de (orgs.). Agroecologia: princípios técnicos para uma agricultura orgânica sustentável. Brasília: EMBRAPA Informação Tecnológica, 2005, pp. 71-99.; e Lacey, H. A controvérsia sobre os transgênicos: questões científicas e éticas, op. cit., cap. 2.

[11] Analisados de forma breve em EMBRAPA. Marco referencial $\mathrm{em}$ agroecologia, op. cit.

[12] Ver o site da AS-PTA: Assessoria e Serviços a Projetos em Agricultura Alternativa.http://www.aspta.org.br.

[13] As estratégias de pesquisas multi e interdisciplinares em agroecologia são bem adequadas para investigar os riscos indiretos e as incertezas de longo prazo relacionados aos transgênicos, ao passo que integram, na qualidade de componentes, sistemas agroecológicos que também incluem iniciativas de investimento intensivo de capital e pertencentes ao sistema do mercado internacional.

[14] Ver EMBRAPAMarco referencial em agroecologia, op. cit., p. 27; Altieri, Miguel. Agroecologia: a dinâmica produtiva da agricultura sustentável. Porto Alegre: Editora da UFRGS, 1998.

[15] Lacey, H. A controvérsia sobre os transgênicos: questões científicas e éticas, op. cit., pp. 151-7.

[16] Uma vez que as pesquisas relevantes não foram realizadas, é evidente que não há provas científicas disponíveis de que há alternativas; porém, isso não implica a existência de comprovações científicas de que não haja alternativas. 
[17] Tavares, Edson Diogo. "Mensagem de e-mail", 26 set. 2006 . Sou grato ao Edson D. Tavares, agrônomo e membro do grupo de autores da EMBRAPA Marco referencial $\mathrm{em}$ agroecologia, e ao Miguel Guerra, pelas informações úteis.
Quanto à questão sobre se a agroecologia poderia produzir alimento suficiente para a população mundial, considero-a como uma falsa questão.

1. Hoje (segundo dados da FAO) a produção mundial de alimentosé suficiente para alimentar toda a humanidade e ainda sobra. Portanto, o problema não é a produção de alimentos (pois senão não haveria mais fome no mundo) e simo acesso à renda que permita a sua aquisição.

2. A ciência agronômica convencional (modelo da agricultura "moderna" ou baseada na "revolução verde") organizou-se baseada nos seguintes princípios:mecanização, uso de adubos industrializados, uso de agrotóxicos, eseleção de variedades que respondessem às demais tecnologias; tudo isso baseado no uso de combustíveis fósseis que permitiam trazer a agricultura para a lógica e a dinâmica das cadeias produtivas industriais (agora agroindustriais). Tudo isso foipossivel graças a elevados investimentos empesquisa, difusão de tecnologias, crédito, garantia de preços mínimos aos agricultorese subsídios à produção industrial de insumos è sua comercialização e utilização. No Brasil e na maioria dos países em desenvolvimento tudo isso foi promovido com recursos públicos e utilizaram-se como paradigma modelos desenvolvidos em países de clima temperado. Odesenvolvimento de todoesse complexo tem se dado durante os últimos cinqüenta anos. Se a agroecologia tiver todo esse apoio, será que daqui a cinqüenta anos não teremos uma agricultura sustentável?

Voltando para a realidade brasileira, hoje posso the dizer que a agroecologia tem se desenvolvido principalmente em comunidades, cooperativas e organizações de agricultores que não têm acesso a crédito, a assistência técnica nem a tecnologia para seus sistemas de produção que não prescindam de altos investimentos em insumos. Nesse cenário estão se desenvolvendo modelos de agricultura com baixo uso de insumos externos, práticas de rotação e consórcio de culturas, policultivo, práticas de conservação do solo e da água. Modelos que têm permitido a famílias sobreviver, se alimentare se desenvolver sem depender de recursos externos. Se este modelo está dando certo sem apoio estatal, não dará mais certo com apoio? É nisso que estamos pensando na EMBRAPA ${ }^{17}$.

\section{POLÍTICA AGRÍCOLA PÚBLICA}

O argumento apresentado aqui não determina que a utilização de transgênicos em culturas de plantio seja ilegítima ou que, de forma geral, a agroecologia se mostrará a longo prazo uma alternativa melhor que a agricultura baseada em transgênicos. Em vez disso, sustenta que a ciência ainda não solucionou as questões acerca das alternativas. Mais ainda, tendo em vista as pesquisas já realizadas até o presente, o argumento refuta-se aqui a idéia de nega que a autoridade da ciência seja um sustentáculo para legitimar a priorização do desenvolvimento de transgênicos nas políticas agrícolas públicas, e questiona-se que 
essa legitimidade possa ser obtida antes da realização de pesquisas capazes (em princípio) de determinar que a produtividade da agroecologia (e de outras alternativas) seja intrinsecamente limitada. Além disso, estreitar em demasia uma concepção de ciência, restringindo suas metodologias às que se enquadrem na abordagem descontextualizada, inibe, a meu ver, não apenas a realização de pesquisas relevantes, mas também a consciência da sua necessidade ${ }^{18}$.

No entanto, talvez o aspecto mais significativo do meu argumento seja contribuir para o reconhecimento de que as questões de política agrícola pública devam confluir para a seguinte pergunta: "Quais métodos agrícolas ("convencional", transgênico, orgânico, agroecológico, biodinâmico, de subsistência), e em quais combinações e variações, poderiam ser sustentáveis e suficientemente produtivos quando acompanhados de métodos de distribuição viáveis para atender às necessidades de alimentos e nutrientes da população mundial em um futuro previsível?". Esta questão não influencia os resultados das pesquisas, mas permite,embora não garanta, que a agricultura baseada em transgênicos faça parte da resposta ou mesmo do seu núcleo; e, ademais, dá liberdade para que as metodologias apropriadas, como as da biologia moleculare da agroecologia ${ }^{19}$, possam ser determinadas de acordo com as características do objeto da investigação (por exemplo, estrutura genômica ou agroecossistema). Porém, o uso de transgênicos não foi introduzido como resposta a essa pergunta muito abrangente, mas a estas especificamente relacionadas aos transgênicos: "Quais características podem ser inseridas porengenharia genética nas plantas? Quais delas podem serexploradas comercialmente? Autilização de transgênicos pode aumentara produtividade de culturas de forma mais sustentável que o uso dos métodos agrícolas chamados convencionais?". E, em seguida, para responder a questões sobre o valor social geral dos transgênicos: "Como os resultados de pesquisas com transgênicos podem ser utilizados para ajudar a resolver os problemas de pequenos fazendeiros (por exemplo, a produção em agroecossistemas pobres) e suas comunidades (por exemplo, fome e desnutrição) nos países pobres?". Em outras palavras, embora o desenvolvimento dos transgênicos fundamente-se nos resultados comprovados da biologia molecular e da biotecnologia, a tendência da sua aplicação prática é pressupor, sem investigações pertinentes terem sido realizadas, que a disseminação rápida e ampla da agricultura baseada em transgênicos tenha um valor social geral.

Os proponentes do uso de transgênicos preferem concentrar-se nas discussões sobre as questões especificamente relacionadas aos transgênicos, e não considerar a questão mais abrangente proposta no parágrafo anterior, que não pressupõe a importância dos transgênicos, dando a entender que essa é a maneira "científica" a ser adotada. Essa questão, contudo, não está fechada à investigação científica,
[18] Acontece que a autoridade científica exercida de forma apropriada não apóia a concessão de privilégios especiais e pesos indevidos à participação de especialistas em pesquisas biotecnológicas em instituições (como a CTN-Bio) que são responsáveis pelas decisões sobre o uso comercial dos transgênicos e outras inovações de biotecnologia, tampouco a prioridades e a métodos de pesquisa que sejam eticamente admissíveis nas ciências agronômicas e médicas.

[19] Alternativas que rejeitam a utilização de transgênicos podem aproveitar os resultados de pesquisas em biotecnologia, como: de genoma para mapear ecossistemas; de culturas de tecidos para aprimorar a reprodução de plantas que possam ser importantes para ecossistemas sustentáveis; ou do conhecimento do genoma de plantas de cultivo como auxílio a fazendeiros na seleção de variedades para cultivo (Guerra, M.P.; Nodari, R.O.; Reis, M. S. dos; Schmidt, W. "Agriculture, biodiversity and 'appropriate technologies' in Brazil". Ciência e Cultura, n. 50, pp. 408-16, 1998, Guerra, M.P. Nodari, R. O.; Reis, M. S. dos; Orth A.I. "A diversidade dos recursos genéticos vegetais e a nova pesquisa agrícola". Ciência Rural, Santa Maria, n. 28, pp. 521-8, 1998; Lacey, H.A controvérsia sobre os transgênicos: questões científicas e éticas, op. cit., p. 129). O meu argumento levanta questões sobre o uso de transgênicos, mas não exclui a possibilidade de existirem funções indispensáveis da biotecnologia na agricultura, ou funções complementares entre a agricultura intensiva de transgênicos e a agroecologia. Essas funções, todavia, estariam subordinadas a finalidades agrícolas mais amplas, implícitas à questão aberta colocada anteriormente. 
contanto que se reconheça a necessidade de aplicar metodologias que não se limitem somente àquelas que possam ser enquadradas pela abordagem descontextualizada. Além do mais, pode-se questionar o quão "científica" é uma investigação da questão (referente ao uso de transgênicos para abordar o problema da pobreza) que propõe oferecer "soluções" (derivadas das pesquisas sobre a tecnologia de transgênicos) sem considerar o contexto socioeconômico do qual advêm a origem e a manutenção do problema a ser estudado.

Separar a questão mais abrangente das agendas científicas predominantes não é justificável pelos termos da metodologia científica, tampouco pelas finalidades da ciência. Proponho que se possa compreender melhor a questão, levando-se em conta as duas relações de reforço mútuo apresentadas anteriormente: 1 . entre progresso tecnológico e exclusividade da abordagem descontextualizada; e 2. entre comércio e progresso tecnológico. Tudo se passa como se a alegação feita pelos proponentes dos transgênicos, de que não há alternativas, estivesse inquestionavelmente identificada à alegação de que não há alternativas viáveis de cultivo (a não ser em nichos específicos) no âmbito do sistema socioeconômico baseado no capitale no mercado. Isto ajuda a explicaro sentido de inexorabilidade da dominação final do cultivo de transgênicos que aparece em tantas discussões. A alegação de que não há alternativas não reflete conhecimento científico, mas sim poder econômico. E esse aspecto fica oculto quando as políticas sobre o uso de transgênicos são encobertas pelo manto da ciência. Isto também ajuda a explicar por que há obstáculos significativos às pesquisas em agroecologia e aos métodos de cultivo que buscam se desenvolver e expandir. Neste contexto, não é suficiente produzir evidências do potencial produtivo da agroecologia: é necessário torná-la socialmente viável em ampla escala. Contudo, os interesses conjuntos das alianças entre grandes corporações agroindustriais e governos são bem diferentes. O fatoé que as possibilidades da realização bem-sucedida de pesquisas em agroecologia; da expansão e do aperfeiçoamento de cultivos agroecológicos; das atividades e do crescimento de movimentos que englobam os valores representados pelas finalidades da agroecologia (sustentabilidade, fortalecimento popular etc.); e do redirecionamento das prioridades das instituições de pesquisa, estão indissociavelmente interconectadas.

\section{NOVOS ESTUDOS}

CEBRAP

78, julho 2007

pp. 31-39
HUGH LACEY é professor emérito de filosofia no Swarthmore College (Pensilvânia, EUA) e atua com freqüencia como professorvisitante na FFLCH-USP.Ultimamente tem escrito sobre o papel dos valores na pesquisa científica e sobretudo sobre a controvérsia em torno dos transgênicos. 